\title{
Accuracy of second trimester prediction of preterm preeclampsia by three different screening algorithms
}

Authors:

Ahmed Al-Amin ${ }^{1,2}$, Daniel Lorber Rolnik ${ }^{3,4}$, Carin Black ${ }^{5,6}$, Adrienne White ${ }^{5}$, Caroline

Stolarek $^{5}$, Shaun Brennecke ${ }^{5,6}$, Fabricio da Silva Costa ${ }^{2,4}$

1. Pauline Gandel Imaging Centre, Royal Women's Hospital, Parkville, Victoria, Australia

2. Monash Ultrasound for Women, Clayton, Victoria, Australia

3. Perinatal Services, Monash Medical Centre, Clayton, Victoria, Australia

4. Department of Obstetrics and Gynaecology, Monash University, Clayton, Victoria

5. Department of Maternal-Fetal Medicine, Royal Women's Hospital, Parkville, Victoria, Australia

6. Department of Obstetrics and Gynaecology, University of Melbourne, Parkville, Victoria, Australia

Corresponding author:

A/Prof Fabricio da Silva Costa

Department of Obstetrics and Gynaecology, Monash University

246 Clayton Road, Clayton VIC 3168, Australia

fcosta@monashultrasound.com.au

Short title: Second trimester prediction of preeclampsia

Abstract word count: 229 words

Text word count: 2486

Tables: 2

Figures: 1

Key words: Preeclampsia, Screening, Second trimester, Uterine artery Doppler, Mean arterial pressure

This is the author manuscript accepted for publication and has undergone full peer review but has not been through the copyediting, typesetting, pagination and proofreading process, which may lead to differences between this version and the Version of Record. Please cite this article as doi: 10.1111/ajo.12689

This article is protected by copyright. All rights reserved 
The authors disclose no conflicts of interest

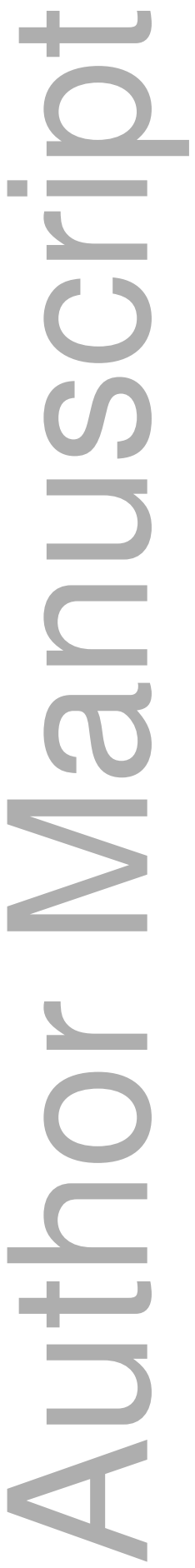

This article is protected by copyright. All rights reserved 
DR. DANIEL LORBER ROLNIK (Orcid ID : 0000-0002-2263-3592)

Article type : Original Manuscript

\section{Accuracy of second trimester prediction of preterm preeclampsia by three different screening algorithms}

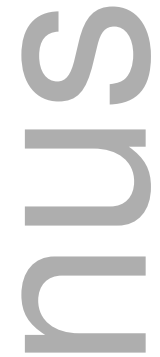

Short title: Second trimester prediction of preeclampsia

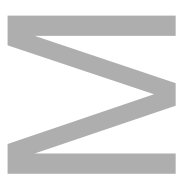

Abstract word count: 229 words

Text word count: 2486

Tables: 2

Figures: 1

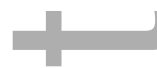

Key words: Preeclampsia, Screening, Second trimester, Uterine artery Doppler, Mean arterial pressure

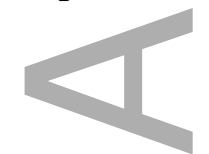

\section{Abstract}

Aim: To compare the performance of three different screening methods (NICE guidelines, ACOG recommendations and FMF algorithm) for second trimester prediction of preeclampsia.

This article is protected by copyright. All rights reserved 
Methods: This was a prospective non-intervention study in singleton pregnancies, including women attending for second trimester morphologic ultrasound at 19-22 weeks. Maternal characteristics, medical history, mean arterial pressure and mean uterine artery Doppler pulsatility index were recorded and used for risk assessment. Outcomes measured were preeclampsia with delivery before 34, before 37 and after 37 weeks' gestation. Detection rates, false positive rates and positive likelihood ratios were calculated, and ROC curves were produced.

Results: We screened 543 women during the study. The incidence of preeclampsia before 34 , before 37 and after 37 weeks was $0.5 \%, 1.4 \%$ and $3.4 \%$, respectively. Detection rates for prediction of preterm preeclampsia were 75\% (95\% CI 34.9-96.8), $87 \%$ (95\% CI 47.3-99.6), 100\% (95\% CI 63.0-100), and 100\% (95\% CI 63.0-100) for NICE guidelines, ACOG recommendations, FMF algorithm with a 1:100 cut-off and FMF algorithm at 1:60 cut-off, respectively. False positive rates were, 22\%, 67\%, 19\% and $12 \%$ for NICE guidelines, ACOG recommendations, FMF algorithm with a 1:100 cut-off and FMF algorithm at 1:60 cut-off, respectively.

Conclusion: Second trimester combined screening for preterm preeclampsia by maternal history, mean arterial pressure and mean uterine artery Doppler pulsatility index (FMF algorithm) was superior than screening by maternal factors alone (NICE guidelines and ACOG recommendations).

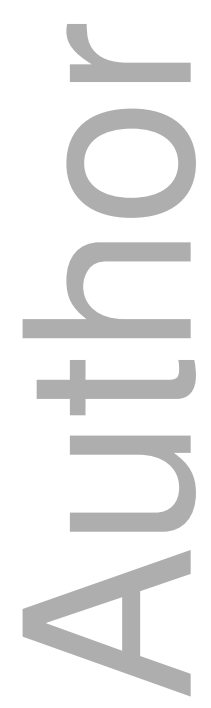




\section{Introduction}

Preeclampsia (PE) affects 2-8\% of all pregnancies and constitutes one of the main causes of maternal and perinatal morbidity and mortality ${ }^{1}$. Identifying women at high risk in the first trimester allows preventive actions such as low-dose aspirin intake starting before 16 weeks $^{2-5}$. In the last few decades, there has been a shift towards early screening for pregnancy complications ${ }^{6}$. However, the number of women attending their first antenatal visit after 16 weeks is often more than 50\% and can be as high as $88.5 \%$ in developing countries, where avoiding complications of the disease remains as a significant challenge ${ }^{7-9}$. Screening for PE in the second trimester could still be of benefit, since close monitoring looking for early signs of PE permits timely treatment and delivery. Additionally, observational data have shown that women who develop PE are at increased lifetime risk of cardiovascular disease, which in turn is related to the severity and to the gestational age at onset of PE, and early identification of such group could facilitate the implementation of prevention strategies postnatally ${ }^{10,11}$.

Different methods of screening have been proposed and used in various healthcare systems. Most of them are based on maternal demographic characteristics and on medical and obstetric history (maternal factors) ${ }^{12-15}$.

The current method of screening in the United Kingdom (UK) National Health System (NHS) is the National Institute for Health and Clinical Excellence (NICE) guidelines, that consider pregnant women to be at high-risk of developing PE if they have any one high-risk factor or any two moderate-risk factors; the high-risk factors are history of hypertensive disease in previous pregnancy, chronic kidney disease, autoimmune disease, diabetes mellitus or chronic hypertension and the moderate-risk factors are first pregnancy, age $>40$ years, inter-pregnancy interval $>10$ years, body mass index (BMI) at first visit of $>35 \mathrm{~kg} / \mathrm{m}^{2}$ or family history of $\mathrm{PE}^{15}$.

In the United States of America (USA), the American College of Obstetricians and Gynecologists (ACOG) states that taking a medical history to evaluate for risk factors is the best and only recommended screening approach for PE; the risk factors are nulliparity, age $>40$ years, body mass index $>30 \mathrm{~kg} / \mathrm{m}^{2}$, conception by in vitro fertilization (IVF), history of previous pregnancy with PE, family history of PE, chronic hypertension, chronic renal disease, diabetes mellitus, systemic lupus erythematosus or thrombophilia ${ }^{12}$. 
However, these traditional methods have poor detection rate or high false positive rate ${ }^{16,}$ 17.

Other authors advocate an alternative method screening based on Bayes theorem, associating maternal history and characteristics with biomarkers such as measurement of mean arterial pressure, uterine artery Doppler pulsatility index (PI) and biochemical markers to generate an individual post-test probability of developing $\mathrm{PE}^{18,19}$.

Such algorithms have higher detection rates with an acceptable false positive rate both in the first and second trimesters for preterm PE prediction ${ }^{18,20,21}$.

A recent study by O'Gorman et al compared the performance of these three methods of screening in the first trimester and reported a higher detection rate with a lower false positive rate when using a patient-specific risk approach ${ }^{16}$. Yet, the performance of individual risk estimation was rarely assessed in different populations in the second trimester.

The aim of this study is to compare the performance of the NICE guidelines ${ }^{15}$, the ACOG recommendations ${ }^{12}$ and a multimarker patient-specific risk assessment using the Fetal Medicine Foundation (FMF) previously published algorithm ${ }^{18}$, including maternal history, MAP and mean uterine artery Doppler PI, in the second trimester (19-22 weeks) for the prediction of PE in the Australian population.

\section{Materials and Methods}

This was a prospective non-intervention study in singleton pregnancies. Women attending for their second trimester morphology ultrasound between 19 and 22 weeks' gestation at The Royal Women's Hospital in Melbourne, Australia, between June 2012 and January 2015 were offered participation in the study.

Maternal demographic characteristics and history were recorded, as well as mean arterial pressure after two measurements in each arm (following previously published technique $)^{22}$. A standardised colour Doppler technique was used to measure the left and right uterine arteries pulsatility index by transabdominal ultrasound and the average value was recorded $^{23,24}$. Each patient was then classified as high or low risk for PE according to the NICE guidelines ${ }^{15}$ and ACOG recommendations ${ }^{12}$. The individual risk for preterm PE according to the FMF algorithm was retrospectively calculated in the end of the study by one of the authors (DR), who was blinded to the outcomes, using a 
previously published algorithm ${ }^{18}$, available at The Fetal Medicine Foundation website (www.fetalmedicine.org).

Outcomes of the pregnancies were determined and the occurrence of PE was confirmed or ruled out by review of medical records. The main outcome measure was preterm PE, as defined by the International Society for the Study of Hypertension in Pregnancy ${ }^{25}$. Detection rates, false positive rates and positive likelihood ratios for detection of PE requiring delivery before 34 weeks, before 37 weeks and after 37 weeks were calculated and receiver operating characteristics (ROC) curves produced with the statistical software package IBM SPSS ${ }^{\circledR}$ for each method of screening.

The study was approved by the Royal Women's Hospital Research and Human Research Ethics Committees (Project approval number 11/23). All the patients involved in the study gave written informed consent.

\section{Results}

In total, 543 women were prospectively screened for PE and had complete outcome data. There were 516 pregnancies without PE and 27 cases (4.9\%) with PE, including three cases $(0.5 \%)$ of PE before 34 weeks, eight cases (1.4\%) of preterm PE and 19 cases of PE at term (3.4\%).

Baseline demographic and clinical characteristics of participants are shown in Table 1. Detection rates (DR), false positive rates (FPR), areas under the curve and positive likelihood ratios for NICE, ACOG and FMF (at cut-off risks of 1:100 and 1:60 for PE before 37 weeks) screening methods are summarized in Table 2. The ROC curves are shown in figure 1.

PE screening by the NICE guidelines detected 33\% (95\% CI 0.84-90.5), 75\% (95\% CI 34.9-96.8) and 47.3\% (95\% CI 24.4-71.1) of PE before 34 weeks, preterm PE and term PE, respectively, with a FPR of $22.4 \%$.

PE screening according to the ACOG recommendations detected 66.6\% (95\% CI 9.499.1), 87.5\% (95\% CI 47.3-99.6) and 89.4\% (95\% CI 66.6-98.7) of PE before 34 weeks, preterm PE and term PE, respectively, with a FPR of $67.8 \%$. Screening for PE using the FMF algorithm at a cut-off of 1:100 detected 100\% of the cases of PE before 34 and 37 weeks (95\% CI 29.2-100 and 63.0-100, respectively) and $42.1 \%$ of term PE cases (95\% CI 20.2-66.5), with a FPR of $19.1 \%$. 
The FMF algorithm at a cut-off of 1:60 detected 100\% of the cases of PE before 34 and 37 weeks (95\% CI 29.2-100 and 63.0-100, respectively) and 26.3\% of term PE cases (95\% CI 9.1-51.2), with a FPR of $12.7 \%$. A cut-off of $1: 25$ would detect $87.5 \%$ of the cases of preterm PE, with a $5 \%$ FPR.

All three methods had a high negative predictive value for preterm PE prediction (> 99\%). There was a statistically significant association between screening positive and developing PE before 37 weeks for NICE guidelines and FMF algorithm $(\mathrm{p}<0.01)$, but not for ACOG recommendations $(\mathrm{p}=0.44)$.

\section{Discussion}

The results of this study demonstrate that combining MAP and mean uterine artery Doppler PI with maternal factors in the second trimester for the calculation of the individual risk of developing preterm preeclampsia is superior to the use of screening methods based only on maternal factors. While history-based methods lead to low detection rates (NICE guidelines) or very high false positive rates including more than half of the population in the high-risk group (ACOG recommendations), patient-specific risk assessment allows detection of a high proportion of the patients that will develop preterm preeclampsia with an acceptable false positive rate. Likelihood ratios were higher for the FMF algorithm than for NICE guidelines and ACOG recommendations, as well as the accuracy expressed by the area under the ROC curves.

It is important to highlight that the addition of MAP and mean uterine artery Doppler PI to maternal factors at the time of 19-22 weeks' foetal assessment, at minimal extra cost and without the addition of biochemical markers to the predictive model, still detected all cases of early-onset and preterm preeclampsia.

Recording maternal history and measurement of blood pressure are widely carried out as part of routine antenatal care; measurement of MAP requires adherence to a specific technique but can easily be performed by healthcare professionals after minimal training and using inexpensive blood pressure devices ${ }^{22}$. Measurement of mean uterine artery Doppler PI requires specific training by sonographers and auditing, but can be done within a few minutes by sonographers during routine second trimester scan ultrasound $^{24}$.

The multimarker screening did not perform well for the detection of term preeclampsia. On the contrary, the ACOG recommendations detected most of the term preeclampsia 
cases, but at the expense of a very high FPR, identifying two thirds of the population as being at increased risk.

Similar findings were recently reported in the first trimester screening for preeclampsia $^{16}$.

Furthermore, risk calculation using Bayes theorem gives clinicians and healthcare systems the opportunity to opt for the best cut-off value in their settings.

Park et al, in 2013, performed a validation of the first trimester FMF multiple logistic regression algorithm for prediction of risk of preeclampsia in an Australian population $^{26}$. However, to our knowledge, this is the first study to evaluate the performance of different methods of screening in Australia and to externally validate the FMF algorithm for second trimester prediction of preeclampsia in our population. The incidence of preeclampsia was equal that reported for the Australian population in previously published studies ${ }^{27}$.

The main limitation of this study was the small number of cases of early-onset and preterm PE, with consequent large 95\% confidence intervals. Nevertheless, the incidence of $\mathrm{PE}$ in our population and the detection and false positive rates obtained were very similar to those previously reported ${ }^{16,19,21,26}$, and all cases delivering before 37 weeks were detected by the multimarker algorithm.

In conclusion, screening for preterm preeclampsia in the second trimester by individual risk calculation using maternal factors, MAP and uterine artery Doppler pulsatility index (FMF algorithm) performs better than screening by maternal factors alone using the NICE guidelines and the ACOG recommendations.

\section{Acknowledgements}

We would like to thank clinicians and administrative staff of the Pauline Gandel Imaging Centre, Royal Women's Hospital, Australia, for their assistance in recruiting patients for the study, and Karen Reidy and Jo Bruhn for their contribution as data managers. 


\section{References}

1 Duley L. The global impact of pre-eclampsia and eclampsia. Semin Perinatol. 2009; 33: $130-7$.

2 Beaufils M, Uzan S, Donsimoni R, Colau JC. Prevention of pre-eclampsia by early antiplatelet therapy. Lancet. 1985; 1: 840-2.

3 Park F, Russo K, Williams P, et al. Prediction and prevention of early-onset preeclampsia: impact of aspirin after first-trimester screening. Ultrasound Obstet Gynecol. 2015; 46: 419-23.

4 Roberge $S$, Demers S, Bujold E. Initiation of aspirin in early gestation for the prevention of pre-eclampsia. BJOG. 2013; 120: 773-4.

5 Rolnik DL, Wright D, Poon LC, et al. Aspirin versus Placebo in Pregnancies at High Risk for Preterm Preeclampsia. N Engl J Med. 2017.

6 Nicolaides KH. Turning the pyramid of prenatal care. Fetal Diagn Ther. 2011; 29: 183-96.

7 Gross K, Alba S, Glass TR, Schellenberg JA, Obrist B. Timing of antenatal care for adolescent and adult pregnant women in south-eastern Tanzania. BMC Pregnancy Childbirth. 2012; 12: 16.

8 Muhwava LS, Morojele N, London L. Psychosocial factors associated with early initiation and frequency of antenatal care (ANC) visits in a rural and urban setting in South Africa: a cross-sectional survey. BMC Pregnancy Childbirth. 2016; 16: 18.

9 Turyasiima M, Tugume R, Openy A, et al. Determinants of First Antenatal Care Visit by Pregnant Women at Community Based Education, Research and Service Sites in Northern Uganda. East Afr Med J. 2014; 91: 317-22.

10 Veerbeek JH, Hermes W, Breimer AY, et al. Cardiovascular disease risk factors after early-onset preeclampsia, late-onset preeclampsia, and pregnancy-induced hypertension. Hypertension. 2015; 65: 600-6.

$11 \mathrm{Wu}$ P, Haththotuwa R, Kwok CS, et al. Preeclampsia and Future Cardiovascular Health: A Systematic Review and Meta-Analysis. Circ Cardiovasc Qual Outcomes. 2017; 10.

12 Committee Opinion No. 638: First-Trimester Risk Assessment for Early-Onset Preeclampsia. Obstet Gynecol. 2015; 126: e25-7.

13 Costa FS, Murthi P, Keogh R, Woodrow N. Early screening for preeclampsia. Rev Bras Ginecol Obstet. 2011; 33: 367-75. 
14 Kane SC, Da Silva Costa F, Brennecke SP. New directions in the prediction of preeclampsia. Aust N Z J Obstet Gynaecol. 2014; 54: 101-7.

15 Visintin C, Mugglestone MA, Almerie MQ, et al. Management of hypertensive disorders during pregnancy: summary of NICE guidance. BMJ. 2010; 341: c2207.

16 O' Gorman N, Wright D, Poon LC, et al. Multicenter screening for preeclampsia by maternal factors and biomarkers at 11-13 weeks' gestation: comparison to NICE guidelines and ACOG recommendations. Ultrasound Obstet Gynecol. 2017.

17 Verghese L, Alam S, Beski S, Thuraisingham R, Barnes I, MacCallum P. Antenatal screening for pre-eclampsia: evaluation of the NICE and pre-eclampsia community guidelines. J Obstet Gynaecol. 2012; 32: 128-31.

18 Gallo DM, Wright D, Casanova C, Campanero M, Nicolaides KH. Competing risks model in screening for preeclampsia by maternal factors and biomarkers at 1924 weeks' gestation. Am J Obstet Gynecol. 2016; 214: 619 e1- e17.

19 O'Gorman N, Wright D, Syngelaki A, et al. Competing risks model in screening for preeclampsia by maternal factors and biomarkers at 11-13 weeks gestation. Am J Obstet Gynecol. 2016; 214: 103 e1- e12.

20 Gabbay-Benziv R, Oliveira N, Baschat AA. Optimal first trimester preeclampsia prediction: a comparison of multimarker algorithm, risk profiles and their sequential application. Prenat Diagn. 2016; 36: 34-9.

21 O'Gorman N, Wright D, Poon LC, et al. Accuracy of competing risks model in screening for pre-eclampsia by maternal factors and biomarkers at 11-13 weeks' gestation. Ultrasound Obstet Gynecol. 2017.

22 Poon LC, Zymeri NA, Zamprakou A, Syngelaki A, Nicolaides KH. Protocol for measurement of mean arterial pressure at 11-13 weeks' gestation. Fetal Diagn Ther. 2012; 31: 42-8.

23 Campbell S, Diaz-Recasens J, Griffin DR, et al. New doppler technique for assessing uteroplacental blood flow. Lancet. 1983; 1: 675-7.

24 Plasencia W, Maiz N, Bonino S, Kaihura C, Nicolaides KH. Uterine artery Doppler at $11+0$ to $13+6$ weeks in the prediction of pre-eclampsia. Ultrasound Obstet Gynecol. 2007; 30: 742-9.

25 Brown MA, Lindheimer MD, de Swiet M, Van Assche A, Moutquin JM. The classification and diagnosis of the hypertensive disorders of pregnancy: 
statement from the International Society for the Study of Hypertension in Pregnancy (ISSHP). Hypertens Pregnancy. 2001; 20: IX-XIV.

26 Park FJ, Leung CH, Poon LC, Williams PF, Rothwell SJ, Hyett JA. Clinical evaluation of a first trimester algorithm predicting the risk of hypertensive disease of pregnancy. Aust N Z J Obstet Gynaecol. 2013; 53: 532-9.

27 Thornton C, Dahlen H, Korda A, Hennessy A. The incidence of preeclampsia and eclampsia and associated maternal mortality in Australia from population-linked datasets: 2000-2008. Am J Obstet Gynecol. 2013; 208: 476 e1-5.

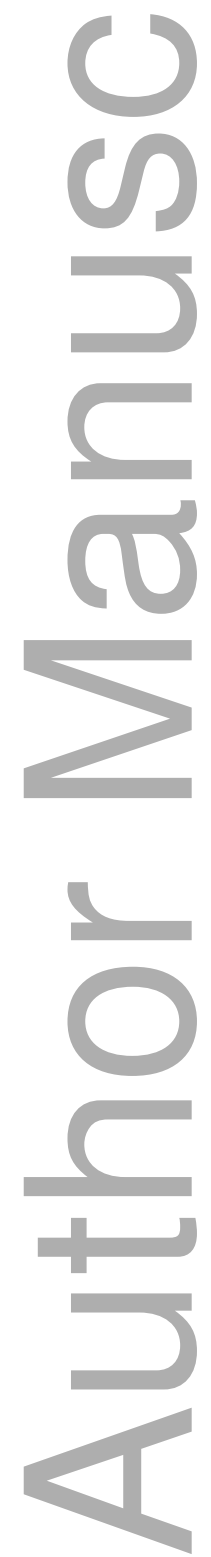


Table 1. Characteristics of study population.

\begin{tabular}{|c|c|c|c|c|}
\hline Maternal characteristics & $\begin{array}{l}\text { No PE } \\
(n=516)\end{array}$ & $\begin{array}{c}\text { PE }<34 \text { weeks } \\
(n=3)\end{array}$ & $\begin{array}{c}\text { PE }<37 \text { weeks } \\
(n=8)\end{array}$ & $\begin{array}{c}\text { PE }>37 \text { weeks } \\
(n=19)\end{array}$ \\
\hline Maternal age in years, median (IQR) & $35(28,42)$ & $36(32,40)$ & $34(27,41)$ & $32(26,38)$ \\
\hline GA in weeks, median (IQR) & $20.3(19.3,21.3)$ & $20.7(20.0,21.4)$ & $20.3(19.3,21.3)$ & $20.4(19.4,21.4)$ \\
\hline Weight in Kg, median (IQR) & $69(53,85)$ & $88.6(72.4,102.8) *$ & $85.5(57.5,113.5) *$ & $69.9(38.9,100.9)$ \\
\hline Height in cm, median (IQR) & $165(156,174)$ & $164(157,171)$ & $163.2(151.2,175.2)$ & $164(158,170)$ \\
\hline BMI, median (IQR) & $25.3(19.3,31.3)$ & $33.7(27.4,40) *$ & $32(24,40) *$ & $28.4(17.4,39.4)$ \\
\hline \multicolumn{5}{|l|}{ Racial origin, n (\%) } \\
\hline Caucasian & $389(75.4)$ & $2(66.7)$ & $5(62.5)$ & $17(89.5)$ \\
\hline Afro-Caribbean & $19(3.7)$ & 0 & $1(12.5)$ & 0 \\
\hline East Asian & $42(8.1)$ & $1(33.3)$ & $1(12.5)$ & $2(10.5)$ \\
\hline South Asian & $43(8.3)$ & 0 & $1(12.5)$ & 0 \\
\hline Mixed & $23(4.5)$ & 0 & 0 & 0 \\
\hline \multicolumn{5}{|l|}{ Medical history, n (\%) } \\
\hline Chronic hypertension & $18(3.5)$ & $1(33.3)$ & $3(37.5) *$ & 0 \\
\hline Diabetes & $23(4.4)$ & $1(33.3)$ & $2(25.0)$ & $3(15.8)$ \\
\hline SLE or APS & $5(0.9)$ & 0 & 0 & $1(5.3)$ \\
\hline Cigarette smoking, n (\%) & $33(6.4)$ & 0 & $1(12.5)$ & $2(10.5)$ \\
\hline Family history of PE, n (\%) & $28(5.4)$ & 0 & 0 & 0 \\
\hline \multicolumn{5}{|l|}{ Conception, n (\%) } \\
\hline Spontaneous & $483(93.6)$ & $2(66.7)$ & $7(87.5)$ & $16(84.2)$ \\
\hline Ovulation drugs & $6(1.2)$ & 0 & 0 & 0 \\
\hline IVF & $27(5.2)$ & $1(33.3)$ & $1(12.5)$ & $3(15.8)$ \\
\hline \multicolumn{5}{|l|}{ Parity, n (\%) } \\
\hline Nulliparous & $222(43.0)$ & $1(33.3)$ & $1(12.5)$ & $13(68.4) *$ \\
\hline Parous: no previous PE & $260(50.4)$ & $2(66.7)$ & $4(50.0)$ & $4(21.1) *$ \\
\hline Parous: previous PE & $34(6.6)$ & 0 & $3(37.5) *$ & $2(10.5)$ \\
\hline
\end{tabular}

PE: preeclampsia; IQR: interquartile range; GA: gestational age; BMI: body mass index; SLE: systemic lupus erythematosus; APS: antiphospholipid syndrome; IVF: in vitro fertilization. * $\mathrm{p}<0.05$ when compared to the unaffected group. 
Table 2. Screening performance according to NICE guidelines, ACOG guidelines and FMF algorithm (at cut-offs of 1:60 and 1:100) for preeclampsia delivering before 34, before 37 and after 37 weeks.

\begin{tabular}{|c|c|c|c|c|c|c|c|c|c|c|}
\hline \multirow{2}{*}{ Method of screening } & \multicolumn{3}{|c|}{ PE < 34 weeks } & \multicolumn{3}{|c|}{ PE $<37$ weeks } & \multicolumn{3}{|c|}{ PE $>37$ weeks } & \multirow[b]{2}{*}{$\operatorname{FPR}(\%)$} \\
\hline & $\begin{array}{c}\text { DR (\%) } \\
(95 \% \mathrm{CI})\end{array}$ & $\begin{array}{c}\text { AUC } \\
(95 \% \mathrm{CI})\end{array}$ & $\begin{array}{c}\text { LR+ } \\
(95 \% \mathrm{CI})\end{array}$ & $\begin{array}{c}\text { DR (\%) } \\
(95 \% \mathrm{CI})\end{array}$ & $\begin{array}{c}\text { AUC } \\
(95 \% \mathrm{CI})\end{array}$ & $\begin{array}{c}\text { LR+ } \\
(95 \% \mathrm{CI})\end{array}$ & $\begin{array}{c}\text { DR (\%) } \\
(95 \% \mathrm{CI})\end{array}$ & $\begin{array}{c}\text { AUC } \\
(95 \% \mathrm{CI})\end{array}$ & $\begin{array}{c}\text { LR+ } \\
(95 \% \mathrm{CI})\end{array}$ & \\
\hline NICE guidelines & $\begin{array}{c}33.3 \\
(0.8-90.5)\end{array}$ & $\begin{array}{c}0.546 \\
(0.20-0.88)\end{array}$ & $\begin{array}{c}1.38 \\
(0.28-6.91)\end{array}$ & $\begin{array}{c}75.0 \\
(34.9-96.8)\end{array}$ & $\begin{array}{c}0.758 \\
(0.58-0.93)\end{array}$ & $\begin{array}{c}3.21 \\
(2.09-4.93)\end{array}$ & $\begin{array}{c}47.3 \\
(24.4-71.1)\end{array}$ & $\begin{array}{c}0.620 \\
(0.48-0.75)\end{array}$ & $\begin{array}{c}2.03 \\
(1.24-3.35)\end{array}$ & 22.4 \\
\hline ACOG recommendations & $\begin{array}{c}66.6 \\
(9.4-99.1)\end{array}$ & $\begin{array}{c}0.489 \\
(0.15-0.81)\end{array}$ & $\begin{array}{c}0.97 \\
(0.43-2.16)\end{array}$ & $\begin{array}{c}87.5 \\
(47.3-99.6)\end{array}$ & $\begin{array}{c}0.595 \\
(0.41-0.77)\end{array}$ & $\begin{array}{c}1.28 \\
(0.98-1.67)\end{array}$ & $\begin{array}{c}89.4 \\
(66.8-98.7)\end{array}$ & $\begin{array}{c}0.607 \\
(0.49-0.71)\end{array}$ & $\begin{array}{c}1.31 \\
(1.11-1.55)\end{array}$ & 67.8 \\
\hline FMF (cut-off 1:100) & $\begin{array}{c}100.0 \\
(29.2-100)\end{array}$ & $\begin{array}{c}0.931 \\
(0.86-0.99)\end{array}$ & $\begin{array}{c}4.82 \\
(4.0-5.6)\end{array}$ & $\begin{array}{c}100.0 \\
(63.0-100)\end{array}$ & $\begin{array}{c}0.973 \\
(0.94-1.0)\end{array}$ & $\begin{array}{c}5.00 \\
(4.22-5.92)\end{array}$ & $\begin{array}{c}42.1 \\
(20.2-66.5)\end{array}$ & $\begin{array}{c}0.632 \\
(0.50-0.76)\end{array}$ & $\begin{array}{c}2.06 \\
(1.19-3.59)\end{array}$ & 19.1 \\
\hline FMF (cut-off 1:60 & $\begin{array}{c}100.0 \\
(29.2-100)\end{array}$ & $\begin{array}{c}0.931 \\
(0.86-0.99)\end{array}$ & $\begin{array}{c}7.11 \\
(5.7-8.7)\end{array}$ & $\begin{array}{c}100.0 \\
(63.0-100)\end{array}$ & $\begin{array}{c}0.973 \\
(0.94-1.00)\end{array}$ & $\begin{array}{c}7.54 \\
(6.07-9.36)\end{array}$ & $\begin{array}{c}26.3 \\
(9.1-51.2)\end{array}$ & $\begin{array}{c}0.632 \\
(0.50-0.76)\end{array}$ & $\begin{array}{c}1.86 \\
(0.85-4.07\end{array}$ & 12.7 \\
\hline
\end{tabular}

PE: Preeclampsia. DR: detection rate. FPR: False positive rate. AUC: Area under the curve. LR+: positive likelihood ratio. 95\% CI: 95\% confidence interval. 


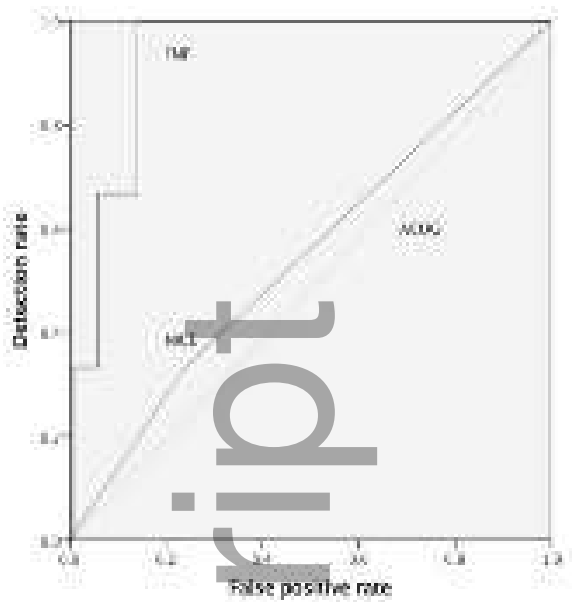

a

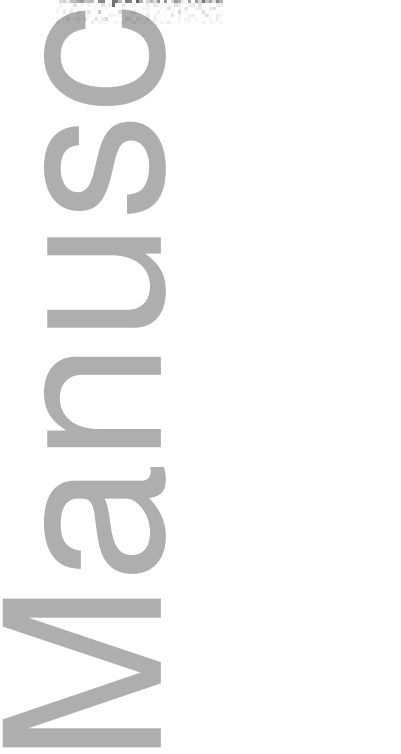

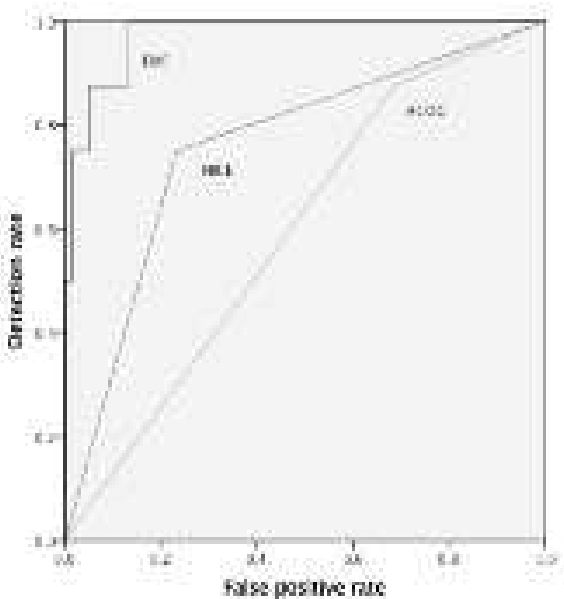

b

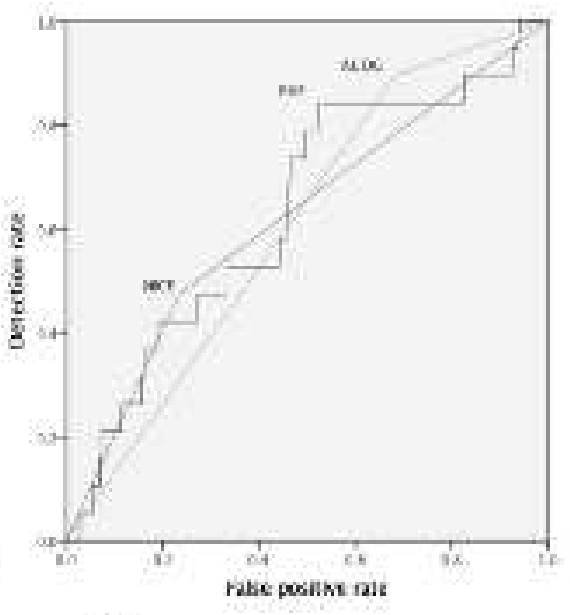

c ajo_12689_f1.tif

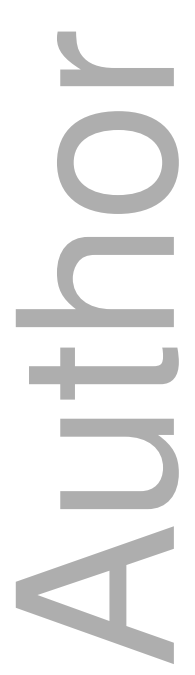




\section{University Library}

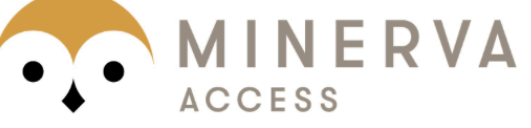

A gateway to Melbourne's research publications

Minerva Access is the Institutional Repository of The University of Melbourne

Author/s:

Al-Amin, A;Rolnik, DL;Black, C;White, A;Stolarek, C;Brennecke, S;Costa, FDS

Title:

Accuracy of second trimester prediction of preterm preeclampsia by three different screening algorithms

Date:

2018-04-01

Citation:

Al-Amin, A., Rolnik, D. L., Black, C., White, A., Stolarek, C., Brennecke, S. \& Costa, F. D. S. (2018). Accuracy of second trimester prediction of preterm preeclampsia by three different screening algorithms. AUSTRALIAN \& NEW ZEALAND JOURNAL OF OBSTETRICS \& GYNAECOLOGY, 58 (2), pp.192-196. https://doi.org/10.1111/ajo.12689.

Persistent Link:

http://hdl.handle.net/11343/293374 